\title{
2018 updated European League Against Rheumatism evidence-based recommendations for the diagnosis of gout
}

\author{
Pascal Richette 주 $, 1,2$ Michael Doherty, ${ }^{3}$ Eliseo Pascual, ${ }^{4}$ Victoria Barskova, ${ }^{5}$ \\ Fabio Becce (1) ${ }^{6}$ Johann Castaneda, ${ }^{7}$ Malcolm Coyfish, ${ }^{8}$ Sylvie Guillo, ${ }^{9}$ Tim Jansen, ${ }^{10}$ \\ Hein Janssens, ${ }^{11}$ Frédéric Lioté, ${ }^{12,13}$ Christian D Mallen, ${ }^{14}$ George Nuki, ${ }^{15}$ \\ Fernando Perez-Ruiz, ${ }^{16}$ José Pimentao, ${ }_{1}^{17}$ Leonardo Punzi, ${ }^{18}$ Anthony Pywell, ${ }_{1}^{8}$ \\ Alexander K So, ${ }^{19}$ Anne-Kathrin Tausche, ${ }^{20}$ Till Uhlig, $^{21}$ Jakub Zavada, ${ }^{22}$ Weiya Zhang, ${ }^{23}$ \\ Florence Tubach, ${ }^{24}$ Thomas Bardin (i) ${ }^{25}$
}

\begin{abstract}
Handling editor Josef $S$
Smolen

- Additional material is published online only. To view please visit the journal online (http://dx.doi.org/10.1136/ annrheumdis-2019-215315).
\end{abstract}

For numbered affiliations see end of article.

\section{Correspondence to}

Professor Pascal Richette, Service de Rhumatologie, Hopital Lariboisiere Centre Viggo Petersen, Paris 75010, France; pascal.richette@aphp.fr

Received 9 March 2019 Revised 24 April 2019 Accepted 25 April 2019 Published Online First 5 June 2019

\section{Check for updates}

(c) Author(s) (or their employer(s)) 2020. No commercial re-use. See rights and permissions. Published by BMJ.

To cite: Richette $P$

Doherty M, Pascual E,

et al. Ann Rheum Dis

2020;79:31-38

\section{ABSTRACT}

Although gout is the most common inflammatory arthritis, it is still frequently misdiagnosed. New data on imaging and clinical diagnosis have become available since the first EULAR recommendations for the diagnosis of gout in 2006. This prompted a systematic review and update of the 2006 recommendations. A systematic review of the literature concerning all aspects of gout diagnosis was performed. Recommendations were formulated using a Delphi consensus approach. Eight key recommendations were generated. A search for crystals in synovial fluid or tophus aspirates is recommended in every person with suspected gout, because demonstration of monosodium urate (MSU) crystals allows a definite diagnosis of gout. There was consensus that a number of suggestive clinical features support a clinical diagnosis of gout. These are monoarticular involvement of a foot or ankle joint (especially the first metatarsophalangeal joint); previous episodes of similar acute arthritis; rapid onset of severe pain and swelling; erythema; male gender and associated cardiovascular diseases and hyperuricaemia. When crystal identification is not possible, it is recommended that any atypical presentation should be investigated by imaging, in particular with ultrasound to seek features suggestive of MSU crystal deposition (double contour sign and tophi). There was consensus that a diagnosis of gout should not be based on the presence of hyperuricaemia alone. There was also a strong recommendation that all people with gout should be systematically assessed for presence of associated comorbidities and risk factors for cardiovascular disease, as well as for risk factors for chronic hyperuricaemia. Eight updated, evidence-based, expert consensus recommendations for the diagnosis of gout are proposed.

\section{INTRODUCTION}

Gout is caused by prolonged hyperuricaemia which leads to the formation of monosodium urate (MSU) crystals that accumulate in joints and other tissues. ${ }^{1}$ It is recognised as the most common form of inflammatory arthritis, ${ }^{2}$ with a prevalence of $0.9 \%$ to $-2.5 \%$ in Europe, ${ }^{34} 3.9 \%$ in the USA ${ }^{5}$ and over $6 \%$ in some Oceanic-Pacific ethnic groups. ${ }^{67}$
The natural history of MSU deposits evolves through a number of stages: asymptomatic MSU crystal deposition during which people have MSU crystal deposition in the absence of gout; gout defined by MSU crystal deposition and clinical disease elements such as gout flare, chronic gouty arthritis and tophi. If present, recurrent gout flares are separated by asymptomatic intervals named intercritical gout. ${ }^{8} 9$

Despite effective treatments, gout is still often misdiagnosed and its management remains suboptimal. $^{3} 1011$ This may explain why the premature mortality among patients with gout remains unimproved over the last decade. ${ }^{12}$

In 2006, the EULAR produced its first evidencebased recommendations for the diagnosis of gout. ${ }^{13}$ The 2006 task force agreed that detection of MSU crystals in synovial fluid (SF) was the gold standard for the diagnosis of gout. Since then, a number of studies have explored the diagnostic value of clinical algorithms and of imaging modalities such as ultrasound (US) or dual-energy CT (DECT). This prompted a revision of the 2006 recommendations following an updated systematic literature review (SLR) and a Delphi process to achieve consensus.

\section{METHODS}

With the approval of the EULAR executive committee, the convenor (TB) along with two coconvenors of the 2006 task force (MD and EP), an epidemiologist (FT) and an academic rheumatologist (PR) formed a steering group to update the 2006 EULAR recommendations for the diagnosis of gout.

This EULAR task force comprised 15 rheumatologists, 1 musculoskeletal radiologist, 2 general practitioners (GPs), 1 research fellow, 2 patients and 3 experts in epidemiology/methodology from 12 European countries. The recommendations were developed according to the standardised operating procedures for the elaboration, evaluation dissemination and implementation of recommendations endorsed by EULAR. ${ }^{14}$

The task force used the same methodology as that used for developing the 2016 EULAR recommendations for the management of gout. ${ }^{15}$ Briefly, the first step was to determine whether the 10 
former EULAR recommendations (2006) for the diagnosis of gout should be retained, modified or abandoned. Subsequently, one research fellow (JC) with the help of an expert in systematic review methodology (SG) performed an SLR by searching for literature published since 1 January 2005 in MEDLINE, EMBASE and Cochrane Library databases (1996) up to June 2013. The quality of evidence and grades of recommendation were determined by PR according to the standards of the Oxford Centre for Evidence-Based Medicine ${ }^{14}$ (see online supplementary material 1). Next, the task force members attended a 2-day meeting during which results of the SLR were presented in an aggregated form. The task force debated and evaluated the evidence presented and formulated a preliminary set of new recommendations. Consensus for eight updated recommendations was then reached following three Delphi rounds undertaken by email after the meeting. Each participant was asked to rate their level of agreement (LoA) with each final recommendation again using a 9-point numerical rating scale (1, totally disagree; 9, fully agree) and could propose a reformulation of the recommendation. Because the delay between the SLR and agreement of final guideline was longer than expected, the SLR was updated up to July 2018 (see online supplementary material 1). The steering group discussed the results of this additional SLR and agreed that a fourth Delphi round was required to gain full support from all participants. Finally, the task force agreed that this additional SLR did not impact the overall content of the recommendations.

\section{RESULTS}

The task force voted unanimously for changes in all items of the 2006 recommendations (see online supplementary material 1). The literature search yielded 1173 records, of which 83 references were analysed (see flow chart, online supplementary material 1). All the previous recommendations were amended to reflect the updated evidence from the SLR. Four Delphi rounds by email were undertaken to establish the final set of eight recommendations (table 1).

Ranking details for level of evidence and grade of recommendation: see online supplementary material 1 . The LoA (mean $\pm \mathrm{SD}$ ) for each recommendation was graded by the task force from 1 (totally disagree) to 9 (fully agree).

\section{RECOMIMENDATIONS}

(1) Search for crystals in SF or tophus aspirates is recommended in every person with suspected gout, because demonstration of MSU crystals allows a definitive diagnosis of gout.

Clinical features of gout are due to host defence mechanisms reacting to MSU crystals. The task force agreed that the gold standard for a diagnosis of gout still relies on the demonstration of MSU crystals in fluid or tophus aspirates, as it has $100 \%$ specificity. Crystals can be detected by polarised light microscopy in SF aspirated from both symptomatic and asymptomatic joints, particularly the first metatarsophalangeal (MTP) joint and joints previously inflamed. This means that a diagnosis of gout can be established even during the asymptomatic intercritical period after, or between gout flares, so called intercritical gout $^{1617}$ (figure 1). This recommendation is also determined by the absence of an alternative validated diagnostic test and a good safety profile. ${ }^{18}$ The recommendation also implies that patients with suspected gout should be referred if needed to a physician with expertise in aspirating and analysing SF. ${ }^{19}$

(2) Gout should be considered in the diagnosis of any acute arthritis in an adult. When SF analysis is not feasible, a clinical diagnosis of gout is supported by the following suggestive features: monoarticular involvement of a foot (especially the first MTP) or ankle joint; previous similar acute arthritis episodes; rapid onset of severe pain and swelling (at its worst in $<24$ hours); erythema; male gender and associated cardiovascular diseases and hyperuricaemia. These features are highly suggestive but not specific for gout.

The task force recognised that identification of MSU crystals in SF can be challenging because joint aspiration and SF analysis require skills and facilities that are not always present in the primary care setting or in the emergency departments. Moreover, handling and storage of SF in certain cases can affect the reliability of analysis, ${ }^{20}{ }^{21}$ and urate lowering therapy (ULT), by dissolving crystals, can impact the sensitivity of MSU detection. ${ }^{17}$ In the previous EULAR recommendations,${ }^{13}$ the first two

\section{Table 1 Final set of eight recommendations for the diagnosis of gout}

\begin{tabular}{|c|c|c|c|c|}
\hline & Recommendations & $\begin{array}{l}\text { Level of } \\
\text { evidence }\end{array}$ & $\begin{array}{l}\text { Grade of } \\
\text { recommendation }\end{array}$ & $\begin{array}{l}\text { Level of } \\
\text { agreement }\end{array}$ \\
\hline 1 & $\begin{array}{l}\text { Search for crystals in synovial fluid or tophus aspirates is recommended in every person with suspected gout, because } \\
\text { demonstration of MSU crystals allows a definitive diagnosis of gout. }\end{array}$ & $2 b$ & B & $8.6 \pm 1.0$ \\
\hline 4 & The diagnosis of gout should not be made on the presence of hyperuricaemia alone. & $2 a$ & B & $8.9 \pm 0.2$ \\
\hline 5 & $\begin{array}{l}\text { When a clinical diagnosis of gout is uncertain and crystal identification is not possible, patients should be investigated by } \\
\text { imaging to search for MSU crystal deposition and features of any alternative diagnosis. }\end{array}$ & $1 \mathrm{~b}$ & A & $8.5 \pm 1.0$ \\
\hline 6 & $\begin{array}{l}\text { Plain radiographs are indicated to search for imaging evidence of MSU crystal deposition but have limited value for the } \\
\text { diagnosis of gout flare. Ultrasound scanning can be more helpful in establishing a diagnosis in patients with suspected gout } \\
\text { flare or chronic gouty arthritis by detection of tophi not evident on clinical examination, or a double contour sign at cartilage } \\
\text { surfaces, which is highly specific for urate deposits in joints. }\end{array}$ & $1 \mathrm{~b}$ & A & $8.2 \pm 0.9$ \\
\hline 8 & $\begin{array}{l}\text { Systematic assessment for the presence of associated comorbidities in people with gout is recommended, including obesity, } \\
\text { renal impairment, hypertension, ischaemic heart disease, heart failure, diabetes and dyslipidaemia. }\end{array}$ & $1 \mathrm{a}$ & A & $8.7 \pm 0.6$ \\
\hline
\end{tabular}




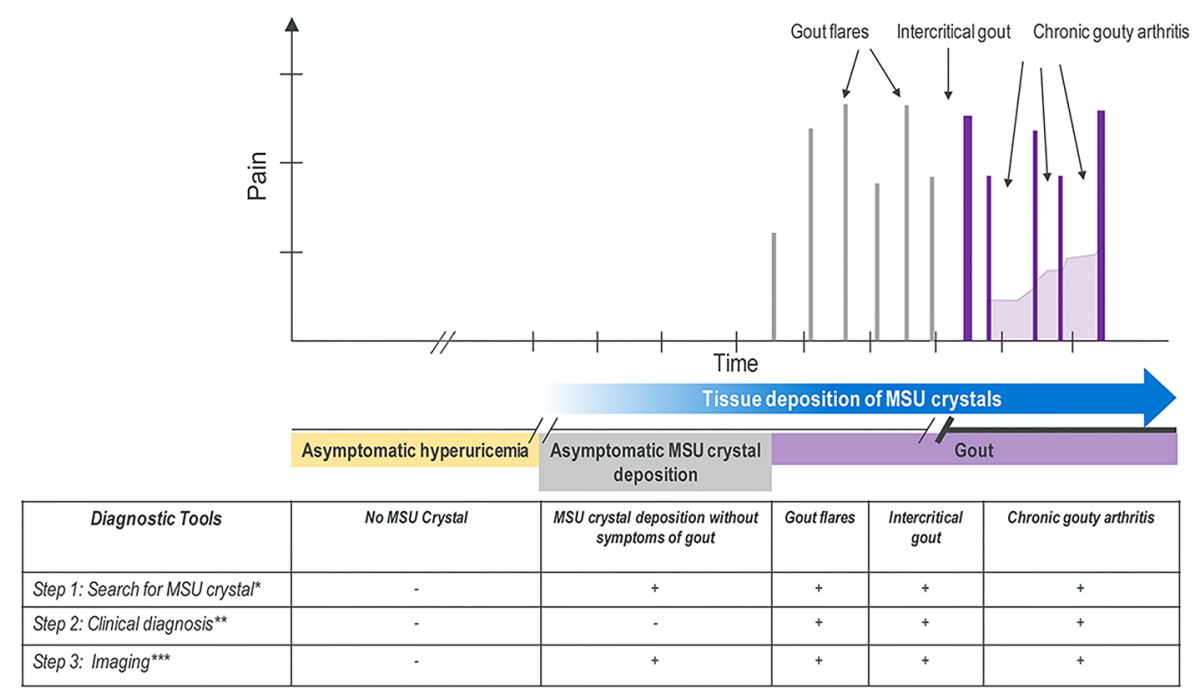

Figure 1 Recommended diagnostic modalities according to the disease states of gout. The figure shows the continuum from preclinical states (asymptomatic hyperuricaemia and then asymptomatic MSU crystal deposition) to gout (clinical states). The EULAR recommends a three-step approach for the diagnosis of gout. *The first step relies on MSU crystal identification in synovial fluid or tophus aspirates; * If not feasible, the second step relies on a clinical diagnosis (based on the presence of hyperuricaemia and associated clinical features of gout); ***The last step recommends imaging, particularly US or DECT, to search for imaging evidence of MSU crystal deposition when a clinical diagnosis of gout is uncertain and crystal identification is not possible. DECT, dual-energy CT; MSU, monosodium urate; US, ultrasound.

recommendations stated that in the absence of SF analysis, a clinical diagnosis of gout can be reasonably made for typical presentations, particularly when patients present with podagra, that is, a gout flare at the first MTP joint. Since then, the predictive values (individually and combined) of typical clinical features of gout have been determined ${ }^{22-25}$ and new classification criteria and algorithms based solely on clinical signs and symptoms have been produced, in patients experiencing ${ }^{2627}$ or not experiencing acute arthritis. ${ }^{28-30}$ Their external validity when compared with SF analysis has also been determined. Overall, both the sensitivities and specificities of these algorithms were greater than $80 \%$

Table 2 Sensitivity and specificity of clinical algorithms published since 2006

MSU crystals in

\section{Demonstration of
MSU crystals in}

cases

\begin{tabular}{|c|c|c|c|}
\hline \multicolumn{4}{|l|}{ Mexico, $2010^{30}$} \\
\hline Vazquez-Mellado et al ${ }^{96}$ & 0.97 & 0.95 & Yes \\
\hline \multicolumn{4}{|l|}{ Taylor et a/ ${ }^{67}$} \\
\hline Less than 2 years & 0.87 & 0.66 & Yes \\
\hline More than 2 years & 0.98 & 0.34 & Yes \\
\hline \multicolumn{4}{|l|}{ Jatuworapruk et a $\left.\right|^{97}$} \\
\hline Less than 2 years & 0.88 & 0.81 & Yes \\
\hline More than 2 years & 0.99 & 0.3 & Yes \\
\hline Netherlands, $2010^{26}$ & & & Yes \\
\hline \multicolumn{4}{|l|}{ Taylor et a $/^{67}$} \\
\hline Less than 2 years & 0.87 & 0.75 & Yes \\
\hline More than 2 years & 0.96 & 0.47 & Yes \\
\hline \multicolumn{4}{|l|}{ Jatuworapruk et al ${ }^{97}$} \\
\hline Less than 2 years & 0.73 & 0.85 & Yes \\
\hline More than 2 years & 0.91 & 0.5 & Yes \\
\hline Paris, $2015^{29}$ & 0.88 & 0.93 & Yes \\
\hline \multicolumn{4}{|l|}{ ACR/Eular, $2015^{28}$} \\
\hline Clinical only & 0.85 & 0.78 & Yes \\
\hline Full set (with imaging) & 0.92 & 0.89 & Yes \\
\hline
\end{tabular}

MSU, monosodium urate. for diagnosis as compared with the gold standard of MSU demonstration in SF (table 2). It must be emphasised, however, that most of these criteria except on $\mathrm{e}^{26}$ are classification criteria ${ }^{28-30}$ and not diagnostic criteria, precluding their use to guide the care of individual patients. ${ }^{31}$ Consequently, the task force included in this recommendation the most discriminating clinical and laboratory features for the diagnosis of gout, based on the results of these studies, apart from imaging, which is considered separately in the fifth and sixth recommendations. However, the task force considered that their specificity was not high enough to replace demonstration of MSU crystals in SF for the diagnosis of gout.

(3) It is strongly recommended that SF aspiration and examination for crystals is undertaken in any patient with undiagnosed inflammatory arthritis.

The rising prevalence of gout makes it the most frequent cause of inflammatory arthritis. Its crude prevalence ranges approximately from $1 \%$ to $4 \%$ in Europe and USA. ${ }^{2}$ As atypical presentations of gout are not rare, and crystal identification allows a definite diagnosis of gout, the task force emphasised the need for SF examination in all cases of undiagnosed inflammatory arthritis.

(4) The diagnosis of gout should not be made on the presence of hyperuricaemia alone.

Epidemiological studies show a relationship between seum uric acid (SUA) levels and incident gout, and that not all hyperuricaemic patients have or will develop gout. ${ }^{32-35}$ For instance, only $22 \%$ of asymptomatic patients with SUA levels above $9 \mathrm{mg} /$ $\mathrm{dL}$ developed incident gout over a 5 -year period. ${ }^{35}$ With MSU crystals identification as reference standard, the specificity of hyperuricaemia for the diagnosis of gout is low, ranging from $53 \%$ to $61 \% .^{23} 26$ Therefore, hyperuricaemia alone should be considered solely as a strong risk factor for incident gout ${ }^{36}$ and not as a surrogate marker for its diagnosis. Conversely, absence of hyperuricaemia has a markedly low negative likelihood ratio, ${ }^{22}$ indicating that after an episode of acute arthritis has settled, the absence of hyperuricaemia does not completely exclude a diagnosis of gout but makes the diagnosis very unlikely. A study found that roughly $10 \%$ of people with gout have SUA levels 
Table 3 Sensitivity and specificity of DECT for the diagnosis of gout

\begin{tabular}{|c|c|c|}
\hline & Sensitivity & Specificity \\
\hline Manger et al $2012^{49}$ & 0.78 & NA \\
\hline Wu et al $2014^{98}$ & 0.97 & 0.87 \\
\hline HJ et al $2015^{99}$ & 0.91 & 0.85 \\
\hline Huppertz et al 2014 $4^{77}$ & 0.78 & 0.93 \\
\hline \multicolumn{3}{|l|}{ Dalbeth et al $2015^{40}$} \\
\hline Early disease ( $\leq 3$ years) & 0.79 & NA \\
\hline Late disease ( $>3$ years) & 0.84 & NA \\
\hline Ahmad et al $2016^{100}$ & 0.82 & 0.89 \\
\hline Kiefer et al $2016^{101}$ & 0.71 & 0.95 \\
\hline Ogdie et al $2015^{43} M A^{*}$ & $0.87(0.79-0.93)$ & $0.84(0.75-0.90)$ \\
\hline Lee and Song $2017^{102} \mathrm{MAt}$ & $0.84(0.81-0.87)$ & $0.93(0.93-0.96)$ \\
\hline
\end{tabular}

Diagnosis of gout, clinical classification criteria only ${ }^{98-101}$; MSU crystal identification

only ${ }^{40} 50103104$; clinical criteria and/or MSU crystal identification. ${ }^{4977}$

*Pooled data from: ${ }^{50} 103104$

t507798-101 103104

DECT, dual-energy CT; MA, meta-analysis; MSU, monosodium urate; NA, not applicable.

below $6 \mathrm{mg} / \mathrm{dL}$ during gout flares. ${ }^{37}$ Thus, the SUA levels have a limited diagnostic value, especially during a gout flare and should be preferably determined at distance from a gout flare. Of note, $15 \%-25 \%$ of people with asymptomatic hyperuricaemia have asymptomatic MSU crystal deposition, ${ }^{38-41}$ a finding which supports the concept that there is, in some people, a continuum from asymptomatic hyperuricaemia to gout ${ }^{92}$ (figure 1). Of note, the definition of hyperuricaemia varies widely across published studies, ranging from 6 to $7 \mathrm{mg} / \mathrm{dL}{ }^{9}$

(5) When a clinical diagnosis of gout is uncertain and crystal identification is not possible, patients should be investigated by imaging to search for MSU crystal deposition and features of any alternative diagnosis.

For patients with atypical clinical features and in whom crystal identification is not feasible, the task force recommends the use of conventional and/or advanced imaging techniques to help the physician diagnose gout. Since the last EULAR recommendations, major advances in imaging of gout have been made, particularly with regard to US, DECT, conventional CT and MRI. ${ }^{43}$ All can detect urate deposition, tophi and bone erosion, but there are still uncertainties about the best imaging modality for diagnosing gout. The task force agreed that although all have their strengths and weaknesses, overall US offers the best potential for diagnosing gout (see the sixth recommendation). DECT is promising and has the advantage of differentiating MSU crystal deposition from connective tissues and from calcium containing mineral deposits by their specific X-ray attenuation properties. ${ }^{43} 44$ DECT can also quantify the MSU crystal deposition burden in and around joints, ${ }^{45-47}$ and explore 'deep-seated' anatomical structures/regions (eg, spine). The metrological properties of DECT for the diagnosis of gout have been assessed in several studies summarised in table 3. It should be noted that many of these studies have included patients at an advanced stage of the disease, that is, patients often with tophaceous and/or erosive gout with chronic gouty arthritis. Sensitivity of DECT in patients with early disease or without tophi tends to be lower. ${ }^{40} 48-50$

(6) Plain radiographs are indicated to search for imaging evidence of MSU crystal deposition but have limited value for the diagnosis of gout flare. US scanning can be more helpful in establishing a diagnosis in patients with suspected gout flare or chronic gouty arthritis by detection of tophi not evident on clinical examination, or a double contour (DC) sign at cartilage surfaces, which is highly specific for urate deposits in joints. Typical radiographic features include: bone erosions with overhanging edges and a sclerotic rim; bone proliferation; joint space narrowing, which occur late in the disease course; and soft-tissue masses, sometimes calcified, corresponding to soft-tissue tophi. Plain radiographic changes take several years to develop, so they may be helpful in supporting a diagnosis of gout in the later stages of the disease. In patients with 4 years duration of disease, sensitivity and specificity for erosions were 0.12 and $0.96{ }^{24}$

US is of major interest for the diagnosis of gout because of its low cost, widespread availability and absence of radiation exposure. Its diagnostic performance with MSU crystal detection as reference test has been assessed in several studies. ${ }^{51-58}$ MSU crystal deposition can be detected in different ways: at the surface of the articular cartilage as a hyperechoic enhancementthe DC sign - within the joint space as floating hyperechoic foci with the appearance of a snowstorm; and within the joint or along tendons as hyperechoic aggregates suggestive of tophi. Sensitivity and specificity of these US features are summarised in table 4. Data from the largest US study showed that these features have high specificity (84\%) and that the DC sign and

Table 4 Sensitivity and specificity of US features for the diagnosis of gout

\begin{tabular}{|c|c|c|c|c|}
\hline & Sensitivity & Specificity & PPV & NPV \\
\hline \multicolumn{5}{|l|}{ Tophus } \\
\hline Ogdie et al $2015^{43} M A^{*}$ & $0.65(0.34-0.87)$ & $0.80(0.38-0.96)$ & & \\
\hline \multicolumn{5}{|l|}{ Ogdie et al $2017^{51}$} \\
\hline Early disease (<2 years) & $0.33(0.25-0.43)$ & $0.95(0.91-0.97)$ & $0.80(0.65-0.90)$ & $0.72(0.66-0.77)$ \\
\hline Late disease ( $\geq 2$ years) & $0.50(0.44-0.56)$ & $0.95(0.91-0.97)$ & $0.93(0.88-0.97)$ & $0.57(0.51-0.62)$ \\
\hline \multicolumn{5}{|l|}{ Double contour sign } \\
\hline Ogdie et al $2015^{43}$ MAt & $0.83(0.72-0.91)$ & $0.76(0.68-0.83)$ & & \\
\hline \multicolumn{5}{|l|}{ Ogdie et al $2017^{51}$} \\
\hline Early disease (<2 years) & $0.50(0.41-0.60)$ & $0.92(0.87-0.95)$ & $0.78(0.67-0.87)$ & $0.77(0.71-0.82)$ \\
\hline Late disease ( $\geq 2$ years) & $0.63(0.57-0.68)$ & $0.91(0.86-0.94)$ & $0.91(0.86-0.94)$ & $0.63(0.57-0.68)$ \\
\hline \multicolumn{5}{|l|}{ Snowtorm appearance } \\
\hline \multicolumn{5}{|l|}{ Ogdie et al $2017^{51}$} \\
\hline Early disease (<2 years) & $0.32(0.23-0.42)$ & $0.90(0.85-0.94)$ & $0.68(0.58-0.77)$ & $0.64(0.60-0.68)$ \\
\hline Late disease ( $\geq 2$ years) & $0.29(0.24-0.35)$ & $0.92(0.89-0.94)$ & $0.88(0.78-0.94)$ & $0.11(0.57-0.19)$ \\
\hline
\end{tabular}

Diagnosis of gout was based on MSU crystal identification in all referenced studies.

*Pooled data from: ${ }^{535-57105}$

$t^{53-56}$

MA, meta-analysis; MSU, monosodium urate; NPV, negative predictive value; PPV, positive predictive value. 
US imaging of tophi perform better than the snowstorm appearance. ${ }^{51}$ Overall, sensitivity of the US features is lower in early versus late disease ${ }^{51}$ (table 4). The US DC sign, the identification of MSU crystal deposition by DECT and imaging evidence of gout-related joint damage with radiographs are all now included in the American College of Rheumatology (ACR)/EULAR 2015 gout classification criteria. ${ }^{28}$

(7) Risk factors for chronic hyperuricaemia should be searched for in every person with gout, specifically: chronic kidney disease (CKD); overweight, medications (including diuretics, low-dose aspirin, cyclosporine and tacrolimus); consumption of excess alcohol (particularly beer and spirits), non-diet sodas, meat and shellfish.

The task force emphasises that once a diagnosis of gout is made, identification of person-specific risk factors for hyperuricaemia is crucial, ${ }^{59-61}$ as some of these are modifiable. For instance, there is evidence that gradual weight loss in obese patients lowers SUA levels and reduces the likelihood of gout flare. ${ }^{62}{ }^{63}$ However, as previously emphasised in the EULAR recommendation for the management of gout, ${ }^{15}$ the level of evidence to support the effect of lifestyle modification alone on SUA levels is low. ${ }^{6465}$ Nevertheless, because of the high prevalence of cardiovascular comorbidities in patients with gout, ${ }^{66}$ implementations of lifestyle modifications are recommended for cardiovascular disease prevention, while prevention of KD and excess alcohol consumption also need to be addressed separately.

(8) Systematic assessment for the presence of associated comorbidities in people with gout is recommended including obesity, renal impairment, hypertension, ischaemic heart disease, heart failure, diabetes and dyslipidaemia.

This recommendation underlines the importance of screening and managing comorbidities frequently associated with gout, as previously emphasised in the EULAR recommendations for the management of gout. ${ }^{15}$ The identification of some of these comorbidities, particularly CKD and cardiovascular diseases is crucial as it has therapeutic implications. ${ }^{15}$

\section{DISCUSSION}

This paper provides eight key recommendations for the diagnosis of gout to all physicians, including GPs, on the basis of an SLR and a Delphi consensus involving both experts and patients.

The task force recommends a three-step approach for the diagnosis of gout (figure 1). The first step relies on MSU crystal identification when SF analysis is feasible. If not possible, the second step relies on a clinical diagnosis based on suggestive and associated clinical features of gout and presence of hyperuricaemia. When a clinical diagnosis of gout is uncertain and crystal identification is not possible, the third step recommends imaging, particularly US, to search for imaging evidence of MSU crystal deposition.

In these updated EULAR recommendations, the identification of crystals using polarising microscopy remains the gold standard for the diagnosis of gout owing to its $100 \%$ specificity. It is a single sufficient criterion for gout classification according to the $2015 \mathrm{ACR} / \mathrm{EULAR}$ gout classification criteria. ${ }^{28}$ However, the task force acknowledges that this may have some limitations in a primary care setting where most patients with gout are diagnosed and treated. Indeed, microscopic SF analysis requires both expertise and equipment that are not readily accessible for all physicians. Another barrier is the required expertise in joint puncture, and the challenge of aspirating SF, without patient discomfort, from small joints or from certain anatomical regions such as the midfoot and wrist.

In patients suffering from acute arthritis and in whom SF analysis is not feasible, the task force recommends that the diagnosis of gout flare should be based both on certain suggestive clinical features and the SUA level. The task force considered that the level of evidence to support the use of any of the published algorithms ${ }^{2628-30}$ was not sufficient for the diagnosis of gout in patients suffering from an acute arthritis. Apart from the Janssens' criteria which were developed for use in clinical practice, ${ }^{26}$ the other recent algorithms ${ }^{28-30}$ were developed to classify patients and not to make a diagnosis at the individual level. In addition, for some of them, ${ }^{26}{ }^{30}$ it has been shown that disease duration impacts on their performance, with lower specificity in established gout. ${ }^{67}$ The six clinical features selected in the second recommendation are derived from several algorithms, particularly the Janssens' rule and the SUGAR study, because these had the best metrological performance among all the assessed variables when compared with crystal identification as reference. ${ }^{2426}$

In the second recommendation, the task force draws attention to the value of SUA levels for the clinical diagnosis of gout. Although there is no accepted definition of hyperuricaemia, ${ }^{9}$ the $6 \mathrm{mg} / \mathrm{dL}$ $(360 \mu \mathrm{M})$ threshold has been proposed because the lifelong risk of gout increases above this level. ${ }^{68}$ In the SUGAR study, the OR of having gout versus not having gout was close to 6 for SUA levels between 6 and $8 \mathrm{mg} / \mathrm{dL}$, while this OR rose to 39 for SUA levels above $10 \mathrm{mg} / \mathrm{dL}^{24}$ However, as highlighted in the fourth recommendation, hyperuricaemia alone should not be used to diagnose gout, and should only be considered when there are suggestive clinical features for the diagnosis of gout. In general, crystallisation of MSU occurs when the SUA level exceeds its saturation point. This is not precisely known but it seems close to $6 \mathrm{mg} / \mathrm{dL}$. However, nucleation and deposition of MSU crystals are very slow processes depending on multiple genetic and environmental factors including tissue nucleators and inhibitors. Among these, persistently high SUA levels are crucial. ${ }^{69}$ Thus, hyperuricaemia is a strong predictor of incident gout but not all patients with asymptomatic hyperuricaemia will develop gout. For instance, a recent study found that only half of patients with SUA levels above $10 \mathrm{mg} /$ $\mathrm{dL}$ will develop gout over 15 years. ${ }^{32}$

The last decade has brought major advances in our understanding of the natural history of gout. In particular, the identification of a continuum between a preclinical state defined by asymptomatic MSU crystal deposition within joints and tendons, and occurrence of the first gout flare (figure 1), has been facilitated by the use of novel imaging such as $\mathrm{US}^{70}$ and DECT. $^{40}$ This new knowledge has prompted the proposal of a novel staging for gout, which allows a diagnosis during the so-called intercritical period. ${ }^{8942}$

Among imaging modalities, US has been the most investigated, particularly in the SUGAR study ${ }^{51}$ and by Outcome Measures in Rheumatology (OMERACT). ${ }^{71-73}$ US features, notably the DC sign, have high specificity and good sensitivity, ${ }^{71-73}$ although the specificity is not so high in early gout. One retrospective study found that the DC sign cannot reliably distinguish gout from calcium pyrophosphate deposition disease. ${ }^{74}$ However, these findings were not subsequently confirmed by Ogdie et al, who found that the DC sign still had a high specificity $92.9 \%(85.8-97.1)$ when compared with subjects with CPDD, ${ }^{51}$ Since the advantages of US include low cost, lack of radiation exposure, ease of use and increasing availability in clinical practices, the task force prioritised US over other imaging modalities. In addition, US can identify associated inflammation using the Doppler mode. ${ }^{58}$ Since the sites for scanning varied across 
studies and because of a lack of standardisation, the task force recommends screening affected joints and at least both first MTP joints and the knees, which are common sites for MSU crystal deposition. US can also facilitate SF aspiration and MSU crystal identification from joints with US evidence for urate deposits, but without clinical effusion or inflammation. ${ }^{75}$

DECT also allows non-invasive detection and characterisation of MSU crystal deposition in joints and soft-tissues. ${ }^{76}$ This technique may be helpful particularly in cases where US is not feasible or technically complicated (eg, spinal gout). However, it is not widely available, and in addition to being expensive and involving some radiation exposure, its use is often restricted to secondary and tertiary care centres. Its diagnostic performance, with MSU crystal identification as reference test, seems comparable to US, with a potential superiority for MSU crystal deposition detection in direct comparison with US. ${ }^{77-80}$ As observed with US, sensitivity for the diagnosis of gout is influenced by the duration of the disease, being lower in the early stage of the disease. ${ }^{40}{ }^{48-50}$ Size and density of tophi also seem to influence the sensitivity for MSU crystal deposition detection. ${ }^{81} 82$ Lastly, reading and interpretation of images from DECT require skill and expertise, and artefacts that could lead to false positivity have been reported. ${ }^{81} 82$

Both US $^{83} 84$ and DECT ${ }^{85}$ could be useful to assess tophus resolution in response to ULT.

MRI and conventional CT both have the ability to identify MSU crystal deposition. However, their diagnostic performance has been less studied than US and DECT. MRI provides information with regard to the size of tophi, crystal-induced inflammation such as synovitis, and joint damage including bone erosion. ${ }^{86-90} \mathrm{CT}$ can also identify urate deposits but is more efficient in visualising bone damage. ${ }^{91-93}$ Therefore, the task force agreed that CT and MRI have limited utility for the diagnosis of gout in clinical practice, as compared with US or DECT.

As in the EULAR recommendations for the treatment of gout, ${ }^{15}$ the task force has emphasised in its two last recommendations the need to search for risk factors for hyperuricaemia once gout is diagnosed. Importantly, some risks factors, notably obesity, ${ }^{63} 94$ medications (diuretics, low-dose aspirin, cyclosporine, tacrolimus) and diet are potentially modifiable. ${ }^{15}$ Lastly, the task force underlines the importance of screening for several comorbidities, in particular obesity, CKD, cardiovascular diseases and components of the metabolic syndrome, which frequently coexist in patients with gout, but for which causality remains controversial. ${ }^{95}$

In conclusion, since the EULAR recommendations for the diagnosis of gout were published in 2006, major advances have been made with regard to imaging, clinical diagnosis and understanding of the natural history of the disease. The EULAR recommendations have therefore been revised and updated in the light of these advances in order to better assist the physicians in diagnosing gout.

\footnotetext{
Author affiliations

${ }^{1}$ Service de Rhumatologie, Hopital Lariboisiere Centre Viggo Petersen, Paris, France ${ }^{2}$ Inserm UMR1132 Bioscar, Universite Paris Diderot UFR de Medecine, Paris, France ${ }^{3}$ Academic Rheumatology, University of Nottingham, Nottingham, UK

${ }^{4}$ Rheumatology, Hospital General Universitario de Alicante, Alicante, Spain

${ }^{5}$ Institute of Rheumatology, RAMS, Moscow, Russian

${ }^{6}$ Radiology, Lausanne University Hospital, Lausanne, Switzerland

${ }^{7}$ AP-HP, Hôpital Pitié-Salpêtrière, Département Biostatistique Santé Publique et Information Médicale, Centre de Pharmacoépidémiologie (Cephepi), INSERM, UMR 1123 ECEVE, CIC-1421, Paris, France, Paris, France

${ }^{8}$ Nottingham, UK

${ }^{9}$ Département d'Epidémiologie et Recherche Clinique, Paris, France

${ }^{10}$ Rheumatology, VieCuri, Venlo, Netherlands
}

${ }^{11}$ Department of Primary and Community Care, Radboud University Medical Center,

Radboud Institute for Health Sciences, Nijmegen, The Netherlands

${ }^{12}$ Department of Rhumatologie, Hôpital Lariboisière, Paris, France

${ }^{13}$ INSERM UMR-1132 and Université Paris Diderot, Paris, France

${ }^{14}$ Arthritis Research UK Primary Care Centre, Keele University, Keele, UK

${ }^{15}$ Centre Molecular Medicine, University of Edinburgh, Edinburgh, UK

${ }^{16}$ Servicio de Reumatologia, Hospital de Cruces, Baracaldo, Spain

${ }^{17}$ Rheumatology Unit, Clínica Coração de Jesus, Lisbon, Portugal

${ }^{18}$ Department of Medicine, University of Padua, Padua, Italy

${ }^{19}$ Musculoskeletal Medicine, Service de RMR, Lausanne, Switzerland

${ }^{20}$ Department of Internal Medicine, Section of Rheumatology, University Clinic Carl Gustav Carus, Dresden, Germany

${ }^{21}$ Rheumatology, Diakonhjemmet Hospital, Oslo, Norway

${ }^{22}$ Institute of Rheumatology, Prague, Czech Republic

${ }^{23}$ Academic Rheumatology, Nottingham University, Nottingham, UK

${ }^{24}$ Biostatistics and epidemiology, APHP, Hopital Pitié Salpetrière, Paris, France

${ }^{25}$ Rheumatology, Assistance Publique - Hopitaux de Paris, Paris, France

Acknowledgements This paper is dedicated to the memory of VB. The task force thanks EULAR for financial and logistic support. Part of this paper was presented as a poster during the Eular Congress (Paris, 2014) (10.1136/annrheumdis-2014eular.5546)

Collaborators Augustin Latourte.

Contributors JC, SG and PR performed the systematic literature review under the supervision of FT. All authors were part of the Task Force, participated in the Delphi rounds and attended the face-to-face meeting. TB organised and chaired the meetings, along with MD and EP. PR wrote the manuscript, with contribution and approval of all coauthors.

Funding This project was funded by the European League Against Rheumatism.

Disclaimer The views expressed are those of the author(s) and not necessarily those of the NHS, the NIHR or the Department of Health and Social Care.

Competing interests PR has received honoraria from Ipsen/Menarini, AstraZeneca, Savient and Grünenthal. MD has received honoraria for ad hoc advisory boards on gout or osteoarthritis from Ardea Biosciences, AstraZeneca, Nordic Biosciences and Roche and was $\mathrm{Cl}$ for a Nottingham University Investigator-led nondrug study on gout funded by AstraZeneca. EP received fees from Ipsen/Menarini and Astra-Zeneca. JC and SG are employed by the Centre de Pharmacoépidémiologie (Cephepi) of the Assistance Publique - Hôpitaux de Paris that has received research funding, grants and fees for consultant activities from a large number of pharmaceutical companies, which have contributed indiscriminately to the salaries of its employees. TJ received fees for lectures and/or advisory boards from Ardea Biosciences, Astra/Zeneca global, Abbvie, BMS, Celgene, Grünenthal, Janssen, Lilly, Menarini International, Novartis, Pfizer, Roche, UCB. FL received fees for advisory boards: Ardea BioSciences, Astra-Zeneca, Ipsen Pharma, Menarini, Novartis, Savient, Mayoly-Spindler. He also received unrestricted grants for organising the European Crystal Network Workshops (Convenor Frédéric Lioté, France\& Alexander So, Switzerland) since 2010: Ardea BioSciences, Astra-Zeneca, Ipsen Pharma, Mayoly-Spindler, Menarini, Novartis, Savient, SOBI. He received fees for lectures from Ardea BioSciences, Grünenthal, Ipsen Pharma, Menarini France, Novartis Global.CDM is funded by the NIHR Collaborations for Leadership in Applied Health Research and Care West Midlands. CDM is also funded by the NIHR School for Primary Care Research and an NIHR Research Professorship in General Practice (NIHR-RP-2014-04-026). NEF, an NIHR Senior Investigator, was funded by an NIHR Research Professorship (NIHR-RP-2011-015). GN has received fees for advisory boards and consultations from Savient, Ipsen, Menarini and Grünenthal and indirectly from Ardea Biosciences and AstraZeneca for work on the IDMC's for trials of lesinurad. FP-R has received fees from AstraZeneca, Grünenthal, Horizon, Menarini, Dyve Biosicence, Japan Tobaco, Logarithm, Astellas. LP has received consulting or speaker fees from Menarini, Fidia, Grünenthal, BMS. AKS has served as consultant to Astra-Zeneca and SOBI in regard to the treatment of gout. A-KT received fees from Berlin Chemie-Menarini, Novartis, AstraZeneca/Ardea Biosciences and Grünenthal Pharma. TU received fees from AstraZeneca/Ardea, Grünenthal Pharma and Novartis JZ received fees from Berlin Chemie-Menarini and Novartis. WZ received honorarium from Savient, AstraZeneca and Grünenthal. FT is head of the Centre de Pharmacoépidémiologie (Cephepi) of the Assistance Publique - Hôpitaux de Paris that has received research funding, grants and fees for consultant activities from a large number of pharmaceutical companies, that have contributed indiscriminately to the salaries of its employees. She did not receive any personal remuneration from these companies. TB has received consulting fees, speaker fees or grants from Ipsen Pharma, Menarini, AstraZeneca, Novartis, Sobi, Savient, Grünenthal and Cymabay.

Patient and public involvement statement Two patients with gout were involved in the elaboration of these recommendations. They participated in the faceto-face meeting, in the Delphi rounds and approved the manuscript.

Patient consent for publication Not required.

Provenance and peer review Not commissioned; externally peer reviewed. 
Data availability statement The data analysed in the current study are available from the corresponding author on request.

\section{ORCID iDs}

Pascal Richette http://orcid.org/0000-0003-2132-4074

Fabio Becce http://orcid.org/0000-0001-8444-8504

Thomas Bardin http://orcid.org/0000-0002-5080-4790

\section{REFERENCES}

1 Dalbeth N, Merriman TR, Stamp LK. Gout. Lancet 2016;388:2039-52.

2 Kuo C-F, Grainge MJ, Zhang W, et al. Global epidemiology of gout: prevalence, incidence and risk factors. Nat Rev Rheumatol 2015;11:649-62.

3 Kuo C-F, Grainge MJ, Mallen C, et al. Rising burden of gout in the UK but continuing suboptimal management: a nationwide population study. Ann Rheum Dis 2015;74:661-7.

4 Bardin T, Bouée S, Clerson P, et al. Prevalence of gout in the adult population of France. Arthritis Care Res 2016;68:261-6.

5 Zhu Y, Pandya BJ, Choi HK. Prevalence of gout and hyperuricemia in the US general population: the National Health and Nutrition Examination Survey 2007-2008. Arthritis \& Rheumatism 2011;63:3136-41.

6 Kuo C-F, Grainge MJ, See L-C, et al. Epidemiology and management of gout in Taiwan: a nationwide population study. Arthritis Res Ther 2015;17.

7 Winnard D, Wright C, Taylor WJ, et al. National prevalence of gout derived from administrative health data in Aotearoa New Zealand. Rheumatology 2012;51:901-9.

8 Bursill D, Taylor WJ, Terkeltaub R, et al. Gout, hyperuricemia, and Crystal-Associated disease network consensus statement regarding labels and definitions for disease elements in gout. Arthritis Care Res 2019;71:427-34.

9 Bardin T, Richette P. Definition of hyperuricemia and gouty conditions. Curr Opin Rheumatol 2014;26:186-91.

10 Doherty M, Jansen TL, Nuki G, et al. Gout: why is this curable disease so seldom Cured? Ann Rheum Dis 2012;71:1765-70.

11 Richette P, Clerson P, Périssin L, et al. Revisiting comorbidities in gout: a cluster analysis. Ann Rheum Dis 2015;74:142-7.

12 Fisher MC, Rai SK, Lu N, et al. The unclosing premature mortality gap in gout: a general population-based study. Ann Rheum Dis 2017;76:1289-94.

13 Zhang W, Doherty M, Pascual E, et al. EULAR evidence based recommendations for gout. Part I: diagnosis. Report of a task Force of the standing Committee for international clinical studies including therapeutics (ESCISIT). Ann Rheum Dis 2006;65:1301-11.

14 van der Heijde D, Aletaha D, Carmona L, et al. Update of the EULAR standardised operating procedures for EULAR-endorsed recommendations. Annals of the rheumatic diseases 2014;2015:8-13.

15 Richette P, Doherty M, Pascual E, et al. Updated EULAR evidence-based recommendations for the management of gout. Annals of the rheumatic diseases 2016;2017:29-42.

16 Pascual E, Doherty M. Aspiration of normal or asymptomatic pathological joints for diagnosis and research: indications, technique and success rate. Ann Rheum Dis 2009;68:3-7.

17 Pascual E, Sivera F. Time required for disappearance of urate crystals from synovial fluid after successful hypouricaemic treatment relates to the duration of gout. Ann Rheum Dis 2007:66:1056-8.

18 Taylor WJ, Fransen J, Dalbeth N, et al. Diagnostic Arthrocentesis for suspicion of gout is safe and well tolerated. J Rheumatol 2016:43:150-3.

19 Pascual E, Sivera F. Why is gout so poorly managed? Ann Rheum Dis 2007:66:1269-70.

20 Graf SW, Buchbinder R, Zochling J, et al. The accuracy of methods for urate crystal detection in synovial fluid and the effect of sample handling: a systematic review. Clin Rheumatol 2013;32:225-32.

21 Kienhorst LBE, Janssens HJEM, Eijgelaar RS, et al. The detection of monosodium urate crystals in synovial fluid after long-term and varying storage conditions. Joint Bone Spine 2015;82:470-1.

22 Sivera F, Andrès M, Falzon L, et al. Diagnostic value of clinical, laboratory, and imaging findings in patients with a clinical suspicion of gout: a systematic literature review. J Rheumatol Supp/ 2014:92:3-8.

23 Malik A, Schumacher HR, Dinnella JE, et al. Clinical diagnostic criteria for gout: comparison with the gold standard of synovial fluid crystal analysis. J Clin Rheumatol 2009;15:22-4

24 Taylor WJ, Fransen J, Jansen TL, et al. Study for updated gout classification criteria: identification of features to classify gout. Arthritis Care Res 2015:67:1304-15.

25 Kienhorst LBE, Janssens HJEM, Fransen J, et al. Arthritis of the first metatarsophalangeal joint is not always gout: a prospective cohort study in primary care patients. Joint Bone Spine 2014;81:342-6.

26 Janssens HJEM, Fransen J, van de Lisdonk EH, et al. A diagnostic rule for acute gouty arthritis in primary care without joint fluid analysis. Arch Intern Med 2010;170:1120-6.
27 Kienhorst LBE, Janssens HJEM, Fransen J, et al. The validation of a diagnostic rule for gout without joint fluid analysis: a prospective study. Rheumatology 2015;54:609-14.

28 Neogi T, Jansen TL, Dalbeth N, et al. Gout classification criteria: an American College of Rheumatology/European League against rheumatism collaborative initiative. Ann Rheum Dis 2015;2015:1789-98.

29 Richette P, Clerson P, Bouée S, et al. Identification of patients with gout: elaboration of a questionnaire for epidemiological studies. Ann Rheum Dis 2015;74:1684-90.

30 Peláez-Ballestas I, Hernández Cuevas C, Burgos-Vargas R, et al. Diagnosis of chronic gout: evaluating the American College of rheumatology proposal, European League against rheumatism recommendations, and clinical judgment. J Rheumatol 2010;37:1743-8.

31 Aggarwal R, Ringold S, Khanna D, et al. Distinctions between diagnostic and classification criteria? Arthritis Care Res 2015:67:891-7.

32 Dalbeth N, Phipps-Green A, Frampton C, et al. Relationship between serum urate concentration and clinically evident incident gout: an individual participant data analysis. Ann Rheum Dis 2018;77:1048-52.

33 Bhole V, de Vera M, Rahman MM, et al. Epidemiology of gout in women: Fifty-twoyear followup of a prospective cohort. Arthritis Rheum 2010;62:1069-76.

34 Lin KC, Lin HY, Chou P. The interaction between uric acid level and other risk factors on the development of gout among asymptomatic hyperuricemic men in a prospective study. I Rheumatol 2000;27:1501-5.

35 Campion EW, Glynn RJ, DeLabry LO. Asymptomatic hyperuricemia. Risks and consequences in the normative aging study. Am J Med 1987;82:421-6.

36 Shiozawa A, Szabo SM, Bolzani A, et al. Serum uric acid and the risk of incident and recurrent gout: a systematic review. The Journal of Rheumatology 2017:44:388-96.

37 Schlesinger N, Norquist JM, Watson DJ. Serum urate during acute gout. J Rheumatol 2009;36:1287-9.

38 Pineda C, Amezcua-Guerra LM, Solano C, et al. Joint and tendon subclinical involvement suggestive of gouty arthritis in asymptomatic hyperuricemia: an ultrasound controlled study. Arthritis Res Ther 2011;13.

39 De Miguel E, Puig JG, Castillo C, et al. Diagnosis of gout in patients with asymptomatic hyperuricaemia: a pilot ultrasound study. Ann Rheum Dis 2012;71:157-8.

40 Dalbeth N, House ME, Aati O, et al. Urate crystal deposition in asymptomatic hyperuricaemia and symptomatic gout: a dual energy CT study. Ann Rheum Dis 2015;74:908-11.

41 Andrés M, Quintanilla M-A, Sivera F, et al. Silent monosodium urate crystal deposits are associated with severe coronary calcification in asymptomatic hyperuricemia: an exploratory study. Arthritis \& Rheumatology 2016;68:1531-9.

42 Dalbeth N, Stamp L. Hyperuricaemia and gout: time for a new staging system? Annals of the Rheumatic Diseases 2014;73:1598-600.

43 Ogdie A, Taylor WJ, Weatherall M, et al. Imaging modalities for the classification of gout: systematic literature review and meta-analysis. Ann Rheum Dis 2015;74:1868-74.

44 Omoumi P, Verdun FR, Guggenberger R, et al. Dual-energy CT: basic principles, technical approaches, and applications in musculoskeletal imaging (Part 2). Seminars in musculoskeletal radiology 2015;19:438-45.

45 Sapsford M, Gamble GD, Aati O, et al. Relationship of bone erosion with the urate and soft tissue components of the tophus in gout: a dual energy computed tomography study. Rheumatology 2017;56:129-33.

46 Towiwat P, Doyle AJ, Gamble GD, et al. Urate crystal deposition and bone erosion in gout: 'inside-out' or 'outside-in'? A dual-energy computed tomography study. Arthritis Res Ther 2016;18.

47 Bayat S, Aati O, Rech J, et al. Development of a dual-energy computed tomography scoring system for measurement of urate deposition in gout. Arthritis Care Res 2016;68:769-75

48 Baer AN, Kurano T, Thakur UJ, et al. Dual-energy computed tomography has limited sensitivity for non-tophaceous gout: a comparison study with tophaceous gout. BMC Musculoskelet Disord 2016;17.

49 Manger B, Lell M, Wacker J, et al. Detection of periarticular urate deposits with dual energy CT in patients with acute gouty arthritis. Ann Rheum Dis 2012;71:470-2.

50 Bongartz T, Glazebrook KN, Kavros SJ, et al. Dual-energy CT for the diagnosis of gout: an accuracy and diagnostic yield study. Ann Rheum Dis 2015:74:1072-7.

51 Ogdie A, Taylor WJ, Neogi T, et al. Performance of ultrasound in the diagnosis of gout in a multicenter study: comparison with monosodium urate monohydrate crystal analysis as the gold standard. Arthritis Rheumatol 2017;69:429-38.

52 Zufferey P, Valcov R, Fabreguet I, et al. A prospective evaluation of ultrasound as a diagnostic tool in acute microcrystalline arthritis. Arthritis Res Ther 2015;17.

53 Naredo E, Uson J, Jiménez-Palop M, et al. Ultrasound-detected musculoskeletal urate crystal deposition: which joints and what findings should be assessed for diagnosing gout? Ann Rheum Dis 2014:73:1522-8.

54 Ottaviani S, Richette P, Allard A, et al. Ultrasonography in gout: a case-control study. Clin Exp Rheumatol 2012;30:499-504.

55 Thiele RG, Schlesinger N. Diagnosis of gout by ultrasound. Rheumatology 2007;46:1116-21. 
56 Lamers-Karnebeek FBG, Van Riel PLCM, Jansen TL. Additive value for ultrasonographic signal in a screening algorithm for patients presenting with acute mono-/oligoarthritis in whom gout is suspected. Clin Rheumatol 2014;33:555-9.

57 Nalbant S, Corominas H, Hsu B, et al. Ultrasonography for assessment of subcutaneous nodules. J Rheumatol 2003;30:1191-5.

58 Stewart S, Dalbeth N, Vandal AC, et al. Ultrasound features of the first Metatarsophalangeal joint in gout and asymptomatic hyperuricemia: comparison with Normouricemic individuals. Arthritis Care Res 2017;69:875-83.

59 Choi HK, Soriano LC, Zhang Y, et al. Antihypertensive drugs and risk of incident gout among patients with hypertension: population based case-control study. BMJ 2012;344:d8190.

60 Wang W, Bhole VM, Krishnan E. Chronic kidney disease as a risk factor for incident gout among men and women: retrospective cohort study using data from the Framingham Heart study. BMJ Open 2015;5:e006843.

61 Bruderer S, Bodmer M, Jick SS, et al. Use of diuretics and risk of incident gout: a population-based case-control study. Arthritis Rheumatol 2014;66:185-96.

62 Nielsen SM, Bartels EM, Henriksen M, et al. Weight loss for overweight and obese individuals with gout: a systematic review of Longitudinal studies. Ann Rheum Dis 2017;76:1870-82.

63 Richette P, Poitou C, Manivet P, et al. Weight loss, xanthine oxidase, and serum urate levels: a prospective longitudinal study of obese patients. Arthritis Care Res 2016;68:1036-42.

64 Holland R, McGill NW. Comprehensive dietary education in treated gout patients does not further improve serum urate. Intern Med J 2015;45:189-94.

65 Moi JHY, Sriranganathan MK, Falzon L, et al. Lifestyle interventions for the treatment of gout: a summary of 2 Cochrane systematic reviews. J Rheumato/ Supp/ 2014;92:26-32.

66 Bardin T, Richette P. Impact of comorbidities on gout and hyperuricaemia: an update on prevalence and treatment options. BMC Med 2017;15.

67 Taylor WJ, Fransen J, Dalbeth N, et al. Performance of classification criteria for gout in early and established disease. Ann Rheum Dis 2016;75:178-82.

68 Bardin T. Hyperuricemia starts at 360 micromoles ( $6 \mathrm{mg} / \mathrm{dL}$ ). Joint Bone Spine 2015;82:141-3.

69 Chhana A, Lee G, Dalbeth N. Factors influencing the crystallization of monosodium urate: a systematic literature review. BMC Musculoskelet Disord 2015;16.

70 Chowalloor PV, Keen HI. A systematic review of ultrasonography in gout and asymptomatic hyperuricaemia. Ann Rheum Dis 2013;72:638-45.

71 Gutierrez M, Schmidt WA, Thiele RG, et al. International consensus for ultrasound lesions in gout: results of Delphi process and web-reliability exercise. Rheumatology 2015:54:1797-805

72 Terslev L, Gutierrez M, Christensen R, et al. Assessing elementary lesions in gout by ultrasound: results of an OMERACT patient-based agreement and reliability exercise J Rheumato/ 2015:42:2149-54.

73 Terslev L, Gutierrez M, Schmidt WA, et al. Ultrasound as an outcome measure in gout. a validation process by the OMERACT ultrasound Working Group. J Rheumatol 2015;42:2177-81.

74 Löffler C, Sattler H, Peters L, et al. Distinguishing gouty arthritis from calcium pyrophosphate disease and other arthritides. J Rheumatol 2015;42:513-20.

75 Slot O, Terslev L. Ultrasound-guided dry-needle synovial tissue aspiration for diagnostic microscopy in gout patients presenting without synovial effusion or clinically detectable tophi. J Clin Rheumatol 2015;21:167-8.

76 Dalbeth N, Nicolaou S, Baumgartner S, et al. Presence of monosodium urate crystal deposition by dual-energy CT in patients with gout treated with allopurinol. Ann Rheum Dis 2018;77:364-70.

77 Huppertz A, Hermann K-GA, Diekhoff T, et al. Systemic staging for urate crystal deposits with dual-energy CT and ultrasound in patients with suspected gout. Rheumatol Int 2014;34:763-71.

78 Gruber M, Bodner G, Rath E, et al. Dual-energy computed tomography compared with ultrasound in the diagnosis of gout. Rheumatology 2014;53:173-9.

79 Zhu L, Wu H, Wu X, et al. Comparison between dual-energy computed tomography and ultrasound in the diagnosis of gout of various joints. Acad Radiol 2015:22:1497-502.

80 Pascart T, Grandjean A, Norberciak L, et al. Ultrasonography and dual-energy computed tomography provide different quantification of urate burden in gout: results from a cross-sectional study. Arthritis Res Ther 2017;19.
81 Mallinson PI, Coupal T, Reisinger C, et al. Artifacts in dual-energy CT gout protocol: a review of 50 suspected cases with an artifact identification guide. AJR Am J Roentgenol 2014;203:W103-W109.

82 Coupal TM, Mallinson PI, Gershony SL, et al. Getting the most from your dual-energy scanner: recognizing, reducing, and eliminating artifacts. AJR Am J Roentgenol 2016;206:119-28.

83 Ebstein $\mathrm{E}$, Forien $\mathrm{M}$, Norkuviene $\mathrm{E}$, et al. Ultrasound evaluation in follow-up of uratelowering therapy in gout: the useful study. Rheumatology 2018

84 Peiteado D, Villalba A, Martín-Mola E, et al. Ultrasound sensitivity to changes in gout: a longitudinal study after two years of treatment. Clin Exp Rheumatol 2017:35:746-51.

85 Araujo EG, Bayat S, Petsch C, et al. Tophus resolution with pegloticase: a prospective dual-energy CT study. RMD Open 2015;1:e000075.

86 McQueen FM, Doyle A, Dalbeth N. Imaging in gout - What can we learn from MRI, CT, DECT and US? Arthritis Res Ther 2011;13.

87 McQueen FM, Doyle A, Reeves Q, et al. Bone erosions in patients with chronic gouty arthropathy are associated with tophi but not bone oedema or synovitis: new insights from a 3 T MRI study. Rheumatology 2014;53:95-103.

88 Carter JD, Kedar RP, Anderson SR, et al. An analysis of MRI and ultrasound imaging in patients with gout who have normal plain radiographs. Rheumatology 2009;48:1442-6

89 Carter JD, Patelli M, Anderson SR, et al. An MRI assessment of chronic synovialbased inflammation in gout and its correlation with serum urate levels. Clin Rheumatol 2015:34:345-51.

90 Buckens CF, Terra MP, Maas M. Computed tomography and MR imaging in Crystalline-Induced arthropathies. Radiol Clin North Am 2017;55:1023-34.

91 Dalbeth N, Clark B, Gregory K, et al. Mechanisms of bone erosion in gout: a quantitative analysis using plain radiography and computed tomography. Ann Rheum Dis 2009;68:1290-5.

92 Dalbeth N, Aati O, Kalluru R, et al. Relationship between structural joint damage and urate deposition in gout: a plain radiography and dual-energy CT study. Ann Rheum Dis 2015:74:1030-6.

93 Dalbeth N, Milligan A, Doyle AJ, et al. Characterization of new bone formation in gout: a quantitative site-by-site analysis using plain radiography and computed tomography. Arthritis Res Ther 2012;14.

94 Dalbeth N, Chen P, White M, et al. Impact of bariatric surgery on serum urate targets in people with morbid obesity and diabetes: a prospective longitudinal study. Ann Rheum Dis 2014;73:797-802.

95 Li X, Meng X, Timofeeva M, et al. Serum uric acid levels and multiple health outcomes: umbrella review of evidence from observational studies, randomised controlled trials, and Mendelian randomisation studies. BMJ 2017;357.

96 Vázquez-Mellado J, Hernández-Cuevas CB, Alvarez-Hernández E, et al. The diagnostic value of the proposal for clinical gout diagnosis (CGD). Clin Rheumatol 2012;31:429-34.

97 Jatuworapruk K, Lhakum P, Pattamapaspong N, et al. Performance of the existing classification criteria for gout in Thai patients presenting with acute arthritis. Medicine 2016;95:e2730.

$98 \mathrm{Wu} \mathrm{H}$, Xue J, Ye L, et al. The application of dual-energy computed tomography in the diagnosis of acute gouty arthritis. Clin Rheumatol 2014;33:975-9.

99 HJ H, Liao MY, LY X. Clinical utility of dual-energy CT for gout diagnosis. Clin Imaging 2015;39:880-5.

100 Ahmad Z, Gupta AK, Sharma R, et al. Dual energy computed tomography: a novel technique for diagnosis of gout. Int J Rheum Dis 2016;19:887-96.

101 Kiefer T, Diekhoff T, Hermann S, et al. Single source dual-energy computed tomography in the diagnosis of gout: diagnostic reliability in comparison to digital radiography and conventional computed tomography of the feet. Eur $J$ Radiol 2016;85:1829-34

102 Lee YH, Song GG. Diagnostic accuracy of dual-energy computed tomography in patients with gout: a meta-analysis. Semin Arthritis Rheum 2017:47:95-101.

103 Choi HK, Burns LC, Shojania K, et al. Dual energy CT in gout: a prospective validation study. Ann Rheum Dis 2012;71:1466-71.

104 Glazebrook KN, Guimarães LS, Murthy NS, et al. Identification of intraarticular and periarticular uric acid crystals with dual-energy CT: initial evaluation. Radiology 2011;261:516-24.

105 Ottaviani S, Allard A, Bardin T, et al. An exploratory ultrasound study of early gout. Clin Exp Rheumatol 2011;29:816-21. 